\title{
DERECHO DE FAMILIA, SUCESORIO \\ Y REGÍMENES MATRIMONIALES
}

\section{Leonor Etcheberry Court}

Profesora de Derecho Civil Universidad Diego Portales

COMPENSACIÓN ECONÓMICA OTORGAda A la Conviviente. Corte SupreMA, 7 DE MARZO DE 2012, N 337-2011

Doña R.E.S.P. demanda de cobro de prestaciones en contra de la sucesión de don M.P.M. conformada por su cónyuge M.G.A. y sus hijos R.M., P.A., F.E. y C.A. todos de apellido P.G., solicitando la suma de \$11.629.600 a título de compensaciones y recompensas o la suma que el tribunal determine, más reajustes y costas. tes:

Sus fundamentos son los siguien-

a) Convivencia entre ella y don M.P.M. durante veintitrés años, momento en que éste fallece.

b) Cónyuge e hijos desde el inicio se encontraban radicados en España.

c) Don M.P.M. tenía diabetes con una serie de complicaciones que hicieron que se dedicara exclusivamente a su cuidado, quedando impedida de ejercer una ocupación lucrativa que le permitiera ahorrar para el futuro. d) Durante más de diez años fue, además, su secretaria y le otorgó mandato con tenencia y administración de bienes desde el año 1992, el que ejerció por más de diez años.

e) Existencia de una comunidad entre ella y M.P.M., que es necesario liquidar.

La sentencia de primera instancia del Segundo Juzgado Civil de Valparaíso, desestimó de manera íntegra la demanda, sin costas.

La sentencia de la Corte de Apelaciones de Valparaíso, la revocó y acogió de modo parcial la demanda, condenando a la sucesión demandada al pago de la suma de $\$ 4.000 .000$ por concepto de compensación económica.

La Corte Suprema conoce de los recursos de casación en el fondo y en la forma deducidos por la parte demandada.

Recurso de CASACión en la FORMa

Causal artículo $768 \mathrm{~N}^{\circ} 5$ del $C P C$ en relación con el $\mathrm{N}^{\circ} 4$ del artículo 170 del mismo Código. La Corte declara 
sin lugar el recurso por estimar que la sentencia no ha omitido el análisis y la consideración de la prueba rendida, así como las conclusiones que sobre ellas han recaído, tampoco las razones que motivan la aplicación de la equidad al caso concreto.

\section{RECURSO DE CASACIÓN EN EL FONDO}

Vulneración de los siguientes artículos $19,24,102,1698$ inciso $1^{\circ}$ y 1710 del $C C ; 44,45,50,53,59,61$ y 62 de la Ley de Matrimonio Civil.

Respecto de la sentencia que recae en el recurso de casación en el fondo queremos situar este comentario en dos puntos:

a) ¿es posible a través de los 206 principios de equidad con los cuales la sentencia de segunda instancia dice resolver la cuestión de acuerdo con el artículo $170 \mathrm{~N}^{\circ} 5$ del Código de Procedimiento Civil, que el juez actúe arbitrariamente?;

b) ¿Es posible aplicar la compensación económica establecida en los artículos 61 y 62 de la Ley de Matrimonio Civil, por analogía a la situación de autos, como una de las llamadas fuentes de la equidad?

Siguiendo al profesor Agustín Squella podemos dar el siguiente concepto de equidad:

"dícese que un caso jurídicamente relevante de la vida social se resuelve en equidad

cuando, al faltar una ley que lo contemple y regule, o bien al existir una ley que lo regula de un modo que resulta, vago, indeterminado, oscuro, confuso o contradictorio, o bien al existir una ley que lo regule y que de su aplicación puedan seguirse consecuencias notoriamente injustas o inconvenientes que el autor de la ley no previó ni pudo querer que se produjeran y que parece razonable evitar, el juzgador encargado del conocimiento y fallo del caso administra una solución construida sobre la base de la idea que él forja en conciencia acerca de lo que sea justo resolver a propósito del caso de que se trate, para lo cual el juzgador empleará ante todo su prudencia, esto es, su capacidad de deliberar en torno del caso, a fin de verificar y comprender las particulares circunstancias del mismo, viéndose asimismo influenciado en su decisión por diversos factores a los que se puede llamar fuentes de las decisiones equitativas" 1 .

De acuerdo con la definición dada y tal como lo sostiene el considerando vigésimo segundo de la sentencia, los jueces tomaron la equidad

${ }^{1}$ Agustín Souella, Introducción al Derecho, Santiago, Editorial Jurídica de Chile, 2000, pp. 292-293. 
en su función de integrar, para colmar el vacío legal, lo cual concuerda con la definición transcrita, ya que de todos los supuestos en que la equidad puede ser usada sólo debemos centrarnos en aquella parte que dice que una situación relevante de la vida social se resuelve en equidad, al faltar una ley que lo contemple y regule.

Debemos dejar en claro:

"que esto no significa que la solución de equidad se construya arbitrariamente por el juzgador, puesto que, además de lo señalado, es preciso advertir que esa solución vendrá siempre determinada en mayor o menor medida según los casos, por distintos antecedentes o factores que, combinados entre sí y debidamente ponderados por la percepción valorativa del juzgador coadyuvan a formar el criterio de éste"2.

A los factores que se refiere son las llamadas fuentes de las decisiones equitativas, que siendo muchas, es claro, que sin referirse a ella, y al utilizar una figura establecida en nuestra Ley de Matrimonio Civil necesariamente utilizó el razonamiento por analogía, que es una forma de apoyar las decisiones en equidad por parte del juez.

\footnotetext{
${ }^{2}$ SQuella (n. 1), p. 294.
}

LA ANALOGÍA JURÍDICA

OPERA SOBRE LA BASE

DE LOS SIGUIENTES PRESUPUESTOS

a) Un caso jurídicamente relevante de la vida social que no se encuentra previsto ni regulado por la ley.

b) Una hipótesis similar, si bien no idéntica a la anterior, que sí se encuentra previsto y regulado por la ley.

c) Existencia de una semejanza relevante en ambos supuestos y

d) Posibilidad de ofrecer una razón de justicia, o cualquier otro motivo plausible, que haga aconsejable trasladar al caso no previsto ni regulado la solución contemplada para la situación prevista y regulada ${ }^{3}$.

a) Un caso jurídicamente relevante de la vida social que no se encuentra previsto ni regulado por la ley

En este sentido debemos reparar que no es el supuesto de autos el que no se encuentra previsto ni regulado por la ley, es la convivencia de hecho y todas sus posibles consecuencias jurídicas las que no están reguladas en la ley. Los jueces dan un concepto de lo que debemos entender por convivencia de hecho estableciendo en el considerando décimo octavo que es

"la unión entre personas de diferente sexo que no se en-

${ }^{3}$ SQuella (n. 1), p. 486. 
cuentran casadas entre sí, afectividad, relación marital de algún contenido sexual libremente consentida, cierto grado de estabilidad y duración del vínculo, notoriedad, etc.".

Nadie podría dudar que en el fallo en comento entre la demandante y don M.P. existió una convivencia con las características allí señaladas y que las convivencias de hecho en nuestro país son relevantes en la vida social, a pesar de lo cual éstas no han sido reguladas.

El caso que se trata de analogar es la compensación económica establecida en los artículos 61 y 62 de la Ley de Matrimonio Civil, ya que es basándose en esa figura que la Corte le otorga a la demandante la suma de $\$ 4.000 .000$; no usó otro tipo de indemnización, simplemente adaptó los hechos del caso a esta figura. Es cierto que en esta situación, la compensación económica es en caso de muerte de uno de los convivientes y ello no se encuentra regulado en nuestro Derecho; pero son las mismas convivencias las que no lo están; $\mathrm{e}$, incluso, cuando la jurisprudencia ha dado soluciones a la situación patrimonial de los convivientes, la jurisprudencia ha sido clara y así lo señala el considerando décimo octavo,

"la jurisprudencia durante el siglo xx reconoció derechos patrimoniales a los concubinarios, no por el mero hecho de serlo, sino sólo en el even-

Por lo cual la sola convivencia no otorga derecho alguno, la parte debe probar ciertos hechos que lo harían acreedor en este caso a la compensación económica. Cuales son los hechos en los que se basó la jurisprudencia para otorgársela:

a) ese efectivo que entre ambos existía una convivencia con las características señaladas anteriormente durante veintitrés años hasta que falleció el conviviente;

b) la demandante se dedicó al cuidado exclusivo de su conviviente $\mathrm{y}$

c) la demandante no pudo dedicarse a actividades lucrativas durante el concubinato

Con estos antecedentes quizá no habría problema de otorgarle a la conviviente una compensación económica, pero para que la analogía se encuentre completa debemos analizar los restantes presupuestos.

b) Un caso similar, si bien no idéntico al anterior, que sí se encuentra previsto y regulado por la ley

El caso similar al que se refiere la sentencia es la compensación económica establecida en la Ley de Matrimonio Civil, la cual se aplica cuando el 
matrimonio termina por nulidad o divorcio; cuando uno de los cónyuges se ha dedicado al cuidado de los hijos o a las labores propias del hogar común, uno de los cónyuges no pudo desarrollar una actividad remunerada o lo hizo en menor medida de lo que podía y quería, por lo cual se le debe compensar el menoscabo económico sufrido por esta causa.

Las diferencias respectos de esta institución y el caso de autos serían las siguientes:

a) INEXISTENCIA DE UN MATRIMONIO, los jueces tratan de igualar la convivencia de hecho dándole las características ya expuestas, al matrimonio, la situación puede ser en la práctica una institución similar, pero el matrimonio tiene un reconocimiento jurídico que la convivencia de hecho hasta el momento en nuestro país no tiene, lo cual no cabe duda es injusto, sobre todo en situaciones como éstas en que la no existencia de una ley de divorcio hacía imposible muchas veces a los convivientes poder acceder a este estatuto matrimonial, claro que en la época en que falleció el conviviente tampoco existía compensación económica.

b) LA COMPENSACIÓN ECONÓMICA SE APLICA SOLO EN CASO DE DIVORCIO O NULIDAD DEL MATRIMONIO, no en el caso de la muerte del cónyuge, aquí es claro que los jueces van aún más lejos y hacen aplicable la institución a un supuesto no previsto para el matrimonio, cual es la muerte, lo que también marca una diferencia clara entre esta compensación y la otorgada por los jueces. Por qué no es necesaria aplicarla en caso de muerte, porque el cónyuge tiene amplios derechos hereditarios que le asegurarán su porvenir, seguramente en una forma muy superior a una compensación económica.

c) El menoscabo económico QUE DEBE EXISTIR, aquí debemos establecer que no es el divorcio o nulidad lo que le causa el menoscabo, sino la muerte del conviviente, por lo tanto debemos tratar de construir éste con los hechos establecidos. Siguiendo a Álvaro $\mathrm{Vidal}^{4}$ para determinar este menoscabo debemos analizar el pasado y futuro de, en este caso, la conviviente: PASADO: este empobrecimiento se produce durante el matrimonio, o en términos más precisos: la convivencia, según los dichos de la actora ella se desempeñó como secretaria en su actividad de

${ }^{4}$ Álvaro VIDAL, "El menoscabo económico como elemento central de la compensación económica, en Cuadernos de Análisis Jurídicos, Santiago, Ediciones Universidad Diego Portales, 2009, vol. v, pp. 144-145. 
administrador de edificios desde el año 1989 en adelante y le otorgó un poder amplio, con tenencia y administración de bienes desde 1992 el que ejerció por más de diez años, por lo cual ya no queda claro si se dedicó exclusivamente al cuidado del conviviente o a cuidarlo y a efectuar estos trabajos, si trabajó y acrecentó el patrimonio de su conviviente es claro que hay una comunidad que liquidar y no una compensación económica que pagar. Entendemos que la Corte entendió probada alguna otra actividad que pudo realizar y que dejó de hacerlo. Futuro: la pérdida de los beneficios que implica el estatuto protector del matrimonio, que en este caso no se tenía por no existir un matrimonio, y una carencia patrimonial que producirá sus efectos nocivos hacia el futuro. En el fallo en comento de autos nos encontramos frente a una convivencia, por lo cual la salud, los beneficios previsionales no cambian de ninguna forma al morir el conviviente; ella, además, sostiene que fue quien sostuvo el hogar con lo cual logró mantener el patrimonio de su conviviente intacto, lo cual le impidió ahorrar, pero el cómo se desenvuelve la vida en pareja no es asunto a tener presente para fijar la compensación económica.
De acuerdo con sus dichos ella participó de modo activo en las actividades laborales de su conviviente, por lo cual se puede entender que se encuentra dentro del mercado laboral. Desde este punto de vista no queda claro cuál es el menoscabo económico que se le produce por la muerte del conviviente. Creemos que aquí claramente hay un problema patrimonial que debió ser resuelto de otra forma.

\section{c) Existencia de una semejanza relevante en ambos casos y}

Ahora debemos preguntarnos después de analizar las diferencias, ¿̇cuál es la semejanza relevante en ambos casos?

Creemos que la semejanza relevante es la similitud que existe fácticamente entre la convivencia de hecho y el matrimonio, pero en lo jurídico, lamentablemente no podemos forzar que todas las instituciones creadas para el matrimonio sean aplicadas a la convivencia de hecho, por mucho que estemos de acuerdo en que éstas sean legisladas de forma conveniente. En este punto deberíamos preguntarnos, ¿por qué la jurisprudencia ha recurrido a figuras como la comunidad, la sociedad de hecho, etc, y nunca ha pretendido aplicar una especie de sociedad conyugal o participación en los gananciales para resolver los problemas patrimoniales de las convivencias de hecho?, por ser la convivencia semejante al matrimonio, simplemente 
porque los hechos en que descansan unos y otros son muy diferentes.

La demandante se dedicó al cuidado de su conviviente, lo cual no hay duda, pero al mismo tiempo trabajaba y lograba que el patrimonio de él no se tocara, contribuyó ella a acrecentar el patrimonio de él, pero ése no es algo a tomar en cuenta en una compensación económica, sobre todo cuando la base de ésta es no haber trabajado o haberlo hecho en menor medida, suponiendo que lo hizo de forma gratuita y que todo lo que ganó lo gastó en la vida diaria junto a su conviviente, todavía tenemos que resolver el problema del menoscabo económico que no es claro.

d) Posibilidad de ofrecer una razón de justicia, o cualquier otro motivo plausible, que haga aconsejable trasladar al caso no previsto ni regulado la solución contemplada para el caso previsto y regulado

Creemos que los hechos del caso no varía de los restantes de convivencias de hecho que conocen muestro tribunales, esto se trata simplemente de reconocer una comunidad entre los convivientes y liquidarla.

¿Por qué el tribunal le otorga sin más la cuarta parte de los bienes?, ellos debieron justificar el monto de acuerdo con las prestaciones establecidas en el artículo 62 , pero no se refirieron para nada a ellas, sólo fijaron la suma de $\$ 4.000 .000$ como si fuera una indemnización cualquiera y no una compensación económica con normas claras en cuanto a la for- ma de fijarla, lo que parece acercarse más a la razón es que ésta es la suma de la cual una persona puede disponer libremente para después de sus días, esto es, corresponde a la cuarta de libre disposición; es necesario preguntarse entonces, ¿̇por qué el conviviente no testó esta parte a favor de la demandante después de veintitrés años de convivencia?, por lo que hemos apreciado estamos frente a una pareja de un nivel cultural o, por lo menos, jurídico medio, por lo cual el hecho de testar no le puede haber sido desconocido.

Si bien estamos por legislar a favor de las parejas de hecho, no creemos que aplicar figuras propias establecidas para el matrimonio ayuden a ello, ya que tal como lo señalamos el aplicar principios de equidad, no significa aplicar de modo arbitrario lo que al juez le parezca y si se aplica para la solución del caso una figura contemplada en la legislación, necesariamente se debe reconocer que la integración se ha llevado cabo a través del razonamiento analógico, como fuente de las decisiones equitativas, de acuerdo con lo analizado no creemos que se cumplan en este caso los presupuestos de este razonamiento.

\section{BibliografÍA}

SQuella, Agustín, Introducción al Derecho, Santiago, Editorial Jurídica de Chile, 2000.

VIDAL, Álvaro, "El menoscabo económico como elemento central de la 
compensación económica, en Cuadernos de análisis jurídicos, Santiago, Ediciones Universidad Diego Portales, 2009, vol. v.

IMPUGNACIÓN DE PATERNIDAD. CORTE de Apelaciones de San Miguel, 16 DE FEBRERO DE 2012, ROL 863/2011.

Don J.J.F.V. y doña A.H.A.V. demandan sobre acción de impugnación y nulidad de reconocimiento a don J.P.F.A y doña N.A.B.M.

Los demandantes son los padres del demandado y basan su petición en el artículo 216 inciso final; señalan que existen, además, dos exámenes de $0,0 \%$ sobre la posibilidad que el demandado sea el padre del menor F.A.F.B; sin embargo, el demandado reconoció al menor voluntariamente el 18 de octubre de 2008, y no interpuso la acción de nulidad del reconocimiento por algún vicio del consentimiento dentro del plazo establecido.

En primera instancia, el Primer Juzgado de Familia de Puente Alto rechazó las acciones intentadas; los demandantes apelaron y conociendo de ese recurso el tribunal dicta la sentencia a la que nos referiremos.

El fallo reconoce que los principios recogidos en la normativa de filiación son la igualdad, la identidad y el interés superior del niño, y sobre la base de ellos estima que se debe acoger el recurso de apelación, dejando al niño sin filiación

respecto del padre que lo reconoció voluntariamente $y$, por ende, sin la pensión de alimentos, bastante baja, que se le había fijado. Veremos cómo se puede dilucidar lo que el tribunal entendió que hacía, que protegiendo esos principios establecidos en favor de los niños, llega a esas nefastas consecuencias en el caso de autos.

En cuanto al derecho a la identidad, debemos afirmar que éste se encuentra consagrado en la convención de los Derechos del Niño en sus artículo 7 y 8 , por lo tanto, forma parte del ordenamiento jurídico chileno, que dicho principio tiene dos aristas, una parte estática que es aquélla formada por los antecedentes genéticos con los que nacemos y dentro de esta parte se ubica el hecho de poder conocer quiénes son nuestros progenitores y en la medida de lo posible a ser cuidado por ellos (como señala el artículo séptimo de la convención); la segunda parte es la dinámica que está compuesta, en cambio por elementos recogidos del medio externo en el proceso que cada individuo realiza para insertarse en la sociedad de que forma parte, muchos de los cuales vienen de nuestros padres y están reconocidos en la institución de la posesión notoria en nuestra legislación civil, que de acuerdo con el artículo 201, le da prioridad sobre las pruebas biológicas. En el considerando séptimo la Corte llega a la conclusión contraria al señalar:

"que la posibilidad de alcanzar la verdad material u objetiva, que es la identidad biológica, 
es de rango superior de aquel estatuto de filiación aparente, ya que constituye un derecho de la personalidad y como tal es inherente al ser humano, sólo por ser tal, en consecuencia se trata de derechos esenciales y primigenios que al legislador únicamente cabe reconocer y garantizar”.

Respecto de este punto estimamos que la Corte hizo todo lo contrario, por sobre la identidad del hijo, protegió los intereses de los abuelos de los cuales ya comentaremos. El hijo había sido reconocido de manera voluntaria por el demandado hace tres años y cuatro meses; durante todo ese tiempo el derecho de identidad del niño estaba completa, tenía un padre y una madre que lo habían reconocido voluntariamente; el padre dejó pasar el plazo que tenía para pedir nulidad por supuestos vicios del consentimiento si éstos hubieran estado presentes al momento de reconocer. Por lo cual no entendemos cómo protegió el derecho a la identidad, la Corte, en el fondo, le dice, usted no tiene la identidad correspondiente, busque la biológica correcta que ésa es la suya, pero por el momento lo dejaremos sin identidad porque eso nos parece más correcto para proteger su futuro. La identidad que tenía este niño tenía prioridad sobre los supuestos intereses de los abuelos y la Corte no se la respetó, es cierto que biológicamente no era la correcta, pero no es la única forma de establecer la identidad de un menor, y éste durante tres años y cuatro meses la tuvo.
La jurisprudencia ha sido constante en aceptar las acciones de impugnación, sólo cuando éstas van acompañadas de la acción de reclamación, de acuerdo con lo establecido en el artículo 208 del $C C$, antes que dejar sin filiación a un niño y todo lo que de ella se desprende, sobre todo cuando el reconocimiento voluntario del padre no ha sido invalidado y se le han prescrito los plazos para hacerlo.

El artículo 216 inciso final señala:

"También podrá impugnar la paternidad determinada por reconocimiento toda persona que pruebe un interés actual en ello, en el plazo de un año desde que tuvo ese interés y pudo hacer valer su derecho".

Respecto del interés que manifiestan los abuelos, por lo menos, debemos relevar lo siguiente: la doctrina en su mayoría ha señalado que el interés debe ser patrimonial, sin embargo, se han aceptado algunas acciones de los abuelos sostenidas en un interés moral que no es el caso. Descartado el interés moral, ya que no se invoca, debemos volver al patrimonial; en el considerando octavo se señala:

"que los demandantes pueden no como una mera expectativa sino por orden de la ley ser alimentantes, cuidadores, guardadores e incluso su patrimonio hereditario se ve comprometido, atendido el carácter imperativo que reglamenta nuestro derecho". 
A este respecto tenemos que entender que si eso conforma el interés, entonces aquél lo tienen los abuelos del menor, desde que se produjo el reconocimiento por parte de su hijo, esto es, el 18 de octubre de 2008, por lo cual debemos forzosamente concluir que la acción de los abuelos se encuentra prescrita desde el 18 de octubre de 2009. La otra posibilidad es entender que todo lo que señala la Corte, que no es una mera expectativa, en efecto lo es, nadie los ha demandado de alimentos, ni para que tengan el cuidado personal, ni para ser guardadores, y por el momento siguen vivos como para dar cabida al problema sucesorio; y en este caso, entonces, el interés no es actual y, por lo tanto, tampoco están legitimados activamente para entablar la acción de autos. Lo único que ha pasado en la actualidad, es que se le ha fijado una pensión de alimentos a quien reconoció al hijo y nada más; nadie se ha dirigido en contra de los abuelos.

Por último, debemos señalar que en el considerando quinto la Corte se refiere al interés superior del niño

"el que constituye el pilar fundamental y marco sobre el cual deben reglamentarse en definitiva las relaciones que emanan de la filiación".

¿A qué interés superior se refiere la Corte?, ¿de cuál niño?, ¿cómo se ha construido para determinar que quitándole la filiación se le está protegiendo este interés superior? Nada de eso sabremos, porque la Corte lo omite.

A este niño se le debió nombrar a un curador para la litis, ya que los intereses entre lo que quiere el padre, qué es su representante y, por ende, los abuelos y los intereses del niño se encuentran totalmente en conflicto, sin embargo, nada de esto se hizo; además, de acuerdo con lo señalado en la sentencia, no se deja constancia que el menor haya sido también demandado, lo cual es imprescindible si se le está impugnando su filiación.

¿Qué es, en definitiva, lo que sucede en estos casos?, el padre reconoce voluntariamente, no pide anular el acto de reconocimiento, ya sea porque pensaba que era su hijo o simplemente dejó transcurrir el plazo; por lo cual le solicita a sus padres que lo hagan amparado en el inciso final del artículo 216; son los intereses de ellos (los abuelos y los padres) los que la Corte protegió y, por el contrario, no respetó el derecho a la identidad, el interés superior del niño, del menor de autos, el que ha quedado sin filiación paterna y sin pensión de alimentos.

\section{BibliogRAFÍA}

SQuelda, Agustín, Introducción al Derecho, Santiago, Editorial Jurídica de Chile, 2000.

VIDAL, Álvaro, "El menoscabo económico como elemento central de la compensación económica, en Cuadernos de Análisis Jurídicos, Santiago, Ediciones Universidad Diego Portales, 2009, vol. v. 